\title{
Assessment of smoking behaviour in the dental setting. A study comparing self-reported questionnaire data and exhaled carbon monoxide levels
}

\author{
Marc Frei • Odette Engel Brügger • Pedram Sendi • \\ Peter A. Reichart - Christoph A. Ramseier • \\ Michael M. Bornstein
}

Received: 18 March 2011 / Accepted: 16 June 2011 /Published online: 30 June 2011

(C) Springer-Verlag 2011

\begin{abstract}
The present study validated the accuracy of data from a self-reported questionnaire on smoking behaviour with the use of exhaled carbon monoxide (CO) level measurements in two groups of patients. Group 1 included patients referred to an oral medicine unit, whereas group 2 was recruited from the daily outpatient service. All patients filled in a standardized questionnaire regarding their current and former smoking habits. Additionally, exhaled CO levels were measured using a monitor. A total of 121 patients were included in group 1, and 116 patients were included in group 2. The mean value of exhaled $\mathrm{CO}$ was $7.6 \mathrm{ppm}$ in the first group and $9.2 \mathrm{ppm}$ in the second group. The mean $\mathrm{CO}$ values did not statistically significantly differ between the two groups. The two exhaled $\mathrm{CO}$ level measurements taken for each patient exhibited very good correlation (Spearman's coefficient of 0.9857). Smokers had a mean difference of exhaled $\mathrm{CO}$ values of $13.95 \mathrm{ppm}$ $(p<0.001)$ compared to non-smokers adjusted for the first or second group. The consumption of one additional pack year
\end{abstract}

\footnotetext{
M. Frei • O. Engel Brügger • P. A. Reichart • M. M. Bornstein ( $\varangle)$ Department of Oral Surgery and Stomatology,

School of Dental Medicine, University of Bern,

Freiburgstrasse 7,

CH-3010 Bern, Switzerland

e-mail: michael.bornstein@zmk.unibe.ch

P. Sendi

Institute for Clinical Epidemiology and Biostatistics,

Basel University Hospital,

Basel, Switzerland

C. A. Ramseier

Department of Periodontology, School of Dental Medicine, University of Bern,

Bern, Switzerland
}

resulted in an increase in CO values of $0.16 \mathrm{ppm}(p=0.003)$. The consumption of one additional cigarette per day elevated the $\mathrm{CO}$ measurements by $0.88 \mathrm{ppm}(p<0.001)$. Based on these results, the correlations between the selfreported smoking habits and exhaled $\mathrm{CO}$ values are robust and highly reproducible. CO monitors may offer a noninvasive method to objectively assess current smoking behaviour and to monitor tobacco use cessation attempts in the dental setting.

Keywords Smoking $\cdot$ Oral diseases $\cdot$ Self-reported $\cdot$ Exhaled carbon monoxide $\cdot$ Smoking cessation $\cdot$ Dental setting

\section{Introduction}

Smoking harms nearly every organ of the body, leading to a range of diseases and premature mortality. Doll and colleagues reported that prolonged cigarette smoking from early adulthood tripled age-specific mortality rates, but cessation at age 50 halved the hazard, and cessation at age 30 avoided almost all of it [1]. There are some 4,000 known chemicals in tobacco smoke, and more than 50 of them are known to cause cancer in humans. The lung is the site considered at highest relative risk of cancer due to smoking [2]. Following lung cancer the highest relative risks are observed for the larynx and oral cavity [3]. A recent metaanalysis analysed the data from 12 studies estimating the oral cancer risk in the USA, Uruguay, Italy, Sweden, India, China, Taiwan and Korea [4]. The reported pooled cancer risk estimate was 3.43 times higher in smokers compared to non-smokers. Besides oral squamous cell carcinoma, other oral diseases that are considered to be related to cigarette smoking include oral leukoplakia, periodontal disease, 
tooth loss, gingival recession and other benign mucosal disorders such as smoker's melanosis and smoker's palate [5-7].

It has been demonstrated that patients expect their oral health professionals to ask about their smoking status as part of the overall health assessment $[8,9]$. To estimate the prevalence and also the quantity of smoking, self-reported information is widely used in medicine. Nevertheless, studies have shown that self-reported data on tobacco use may underestimate the true prevalence [10-12]. To gain objective data on smoking and/or exposure to environmental tobacco smoke, the use of cotinine levels in blood, saliva or urine, and carbon monoxide in the exhaled air were evaluated as potential assessment methods [13]. It has been documented that interventions for tobacco users in the dental setting increase the odds of quitting smoking [9]. Nevertheless, the accuracy of self-reported smoking has never been analysed using biochemical methods for patients seeking dental healthcare. The aim of this study was to investigate the accuracy of self-reported data of the smoking habits through the use of exhaled carbon monoxide level measurements in two different groups of patients in a dental setting: patients referred to the oral medicine unit versus patients from the daily outpatient service.

\section{Materials and methods}

\section{Study sample and clinical examination}

This study was designed as a study with two cohorts of patients to validate the accuracy of data from a self-reported questionnaire on smoking behaviour with the use of exhaled carbon monoxide (CO) level measurements in two different groups of patients. Group 1 included patients referred to the oral medicine unit of the Department of Oral Surgery and Stomatology, University of Bern, for diagnosis and treatment of oral mucosal lesions in the period between September and December 2010. The study protocol was approved by the standing ethics committee for clinical studies in the State of Bern. All patients were examined following the same protocol by residents of the department, including thorough medical history, recent dental/stomatological history, extra- and intraoral examination and oral biopsy and radiographic imaging where necessary. All smokers underwent brief counselling for smoking cessation (behavioural intervention) as recommended in the consensus report of the First European Workshop on Tobacco Use Prevention and Cessation for Oral Health Professionals [14]. In group 2, patients from the daily outpatient service of the Department of Oral Surgery and Stomatology, University of Bern, were included during the same study period.
Assessment of smoking behaviour and questionnaire data

Before commencement of the initial examination, all patients in both groups had to fill out a standardized questionnaire regarding their current and former smoking habits [15]. This questionnaire included the following parameters:

- History of smoking: All patients were asked whether they were non-smokers, former smokers or current smokers. The current and former smokers had to indicate the number of cigarettes smoked per day (including the time period since they started smoking) to allow for calculation of a pack year value. The current smokers were classified into two groups: heavy smokers ( $>10$ cigarettes smoked per day) and light smokers (1-10 cigarettes smoked per day).

- Additionally, in all patients, exhaled CO levels were measured using a monitor device $\left(\mathrm{piCO}^{+}\right.$Smokerlyzer; Bedfont Scientific Ltd., Kent, United Kingdom). To ensure that measurements were standardized, each patient was required to exhale completely, take a deep breath and hold it for $15 \mathrm{~s}$ before exhaling fully and slowly into the mouthpiece of the monitor. Furthermore, each patient was instructed to seal their lips tightly around the mouthpiece so that no air escaped from the measuring device when exhaling $[16,17]$. The device measures the exhaled $\mathrm{CO}$ concentration in parts per million ( $\mathrm{ppm}$ ) with a range from $0-100$. The manufacturer states that the device is accurate to $\pm 2 \%$ based on the repeatability of readings (http://www.bedfont.com/smokerlyzer/pico+). For all study participants, two $\mathrm{CO}$ values were measured to validate the reproducibility of the method. The CO measurements were classified into three groups (based on recommendations by the manufacturer): 0-10 ppm, non-/former smokers; 11-25 ppm, light smokers and $>25$ ppm, heavy smokers.

- All patients were examined in the morning between 8.00 a.m. and 12.00 noon.

\section{Statistical analysis}

First, all data were analysed using descriptive statistics. Between group differences of continuous and categorical variables were compared using the $t$ test, Wilcoxon rank sum test or chi-square test where appropriate. The influence of the current smoking status, cumulated pack year values and number of cigarettes per day on exhaled $\mathrm{CO}$ levels were evaluated using a linear regression model, adjusted for groups 1 and 2 (oral medicine referrals or patients attending the outpatient service).

The significance level chosen for all statistical tests was $p \leq$ 0.05 . All statistical analyses were performed using a software package (Stata 11.1; StataCorp, College Station, TX, USA). 


\section{Results}

Study population

A total of 121 patients were included in group 1 (oral medicine referrals). This group was comprised of 44 male and 77 female participants with a mean age of 58.9 years (minimum 17 years, maximum 84.5 years). In group 2 (outpatient service), a total of 116 patients were included. This group was comprised of 65 male and 51 female participants with a mean age of 44.3 years (minimum 17 years, maximum 90 years).

Questionnaire analysis

Group 1 was comprised of 44 current $(36.4 \%$ of 121 patients included) and 36 former smokers (29.8\%) with a mean pack year value of 21 (range from 0.5 to 105) and a mean of 4.8 cigarettes per day (range from 0 to 40, Table 1). No malignant mucosal disease was diagnosed in any of the included patients. Group 2 was comprised of 44 current (37.9\% of 116 patients included) and 26 former smokers (22.4\%) with a mean pack year value of 10.7 (range from 0.5 to 70 ) and a mean of 4.5 cigarettes per day (range from 0 to 45$)$.

Between both groups of patients analysed, there was a statistically significant difference regarding age $(p<0.0001)$ and gender $(p=0.002)$ with patients being older and more frequently female in the oral medicine referral group. For the distribution of current and former smokers, there was no statistically significant difference between both groups $(p=0.407)$. Regarding the difference in pack year values, the difference between the groups was statistically significant $(p=0.0004)$. Nevertheless, the difference in cigarettes per day was not statistically significant for the smokers in both populations $(p=0.8068)$.

Exhaled CO level analysis

For the two exhaled CO level measurements taken for each patient included in both groups, the data exhibited very good correlation with a Spearman's coefficient of 0.9857 . Because of these almost identical CO values, only the initial measurements were used for further analyses.

In group 1, the mean value of exhaled $\mathrm{CO}$ was $7.6 \mathrm{ppm}$ (range of 0-42 ppm). In group 2, the mean value of exhaled $\mathrm{CO}$ was $9.2 \mathrm{ppm}$ (range of $1-76 \mathrm{ppm}$ ). There was no statistically significant difference in mean $\mathrm{CO}$ values between the two groups analysed $(p=0.8890)$. For both groups, non-smokers had a mean value of $3.06 \mathrm{ppm}$, whereas current smokers had a mean value of $16.97 \mathrm{ppm}$. Former smokers had a mean value of 3.68 ppm (Table 2).

Correlation between self-reported data and exhaled CO levels

In both groups, the highest $\mathrm{CO}$ values were found for current smokers, for patients with higher cumulated pack year values and more cigarettes consumed per day (Table 3). Smokers had a mean difference in exhaled $\mathrm{CO}$ values of 13.95 ppm (95\% CI 11.60-16.30 ppm; $p<0.001)$ compared to non-smokers adjusted for groups 1 and 2. For former smokers compared to never smokers, the difference was not statistically significant with a mean difference of $0.78 \mathrm{ppm}(95 \% \mathrm{CI}-1.82-3.36 \mathrm{ppm} ; p=0.55)$. For all included subjects, the consumption of one pack year more resulted in an increase in exhaled $\mathrm{CO}$ value of $0.16 \mathrm{ppm}$ (95\% CI $0.06-0.26 \mathrm{ppm} ; p=0.003$ ). The consumption of one additional cigarette per day elevated the $\mathrm{CO}$ measurements by 0.88 ppm (95\% CI $0.77-0.98$ ppm; $p<0.001)$.

\section{Discussion}

On a global scale, the use of tobacco products is increasing, although there is a clear trend towards a decrease in highincome countries. Overall in Europe, the prevalence of cigarette smoking has stabilised at approximately $28.6 \%$ in the adult population ( $40 \%$ male versus $18.2 \%$ female). However, there is no visible decline for countries in southern and eastern Europe such as Greece with more than 50\% smokers (male, 63.6\%; female, 39.8\%) [18, 19].

Table 1 Characteristics of the patients in the two groups regarding self-reported data on smoking habits (smoking status, cumulated pack year value and amount of cigarettes smoked per day)

\begin{tabular}{llccccc}
\hline Group & Mean age (95\% CI) & $\begin{array}{l}\text { Never smokers } \\
(\% \text { in group) }\end{array}$ & $\begin{array}{l}\text { Current smokers } \\
(\% \text { in group) }\end{array}$ & $\begin{array}{l}\text { Former smokers } \\
(\% \text { in group })\end{array}$ & Mean py (95\% CI) & $\begin{array}{l}\text { Mean amount of cigarettes } \\
\text { per day (range) }\end{array}$ \\
\hline Group 1 & $58.91 *(56.61-61-20)$ & $41(33.88)$ & $44(36.36)$ & $36(29.75)$ & $21.12 *(16.11-25.92)$ & $4.83(0-40)$ \\
Group 2 & $44.32 *(41-46-47.19)$ & $46(39.66)$ & $44(37.93)$ & $26(22.41)$ & $10.71 *(7.75-13.68)$ & $4.50(0-45)$ \\
\hline
\end{tabular}

Group 1, oral medicine referral group; group 2, outpatient group

py cumulated pack year value, 95\% CI 95\% confidence interval

${ }^{*} p<0.05$, statistically significant difference 
Table 2 Exhaled $\mathrm{CO}$ values (in parts per million) for current smokers, former smokers and non-smokers in both cohorts $(n=237)$

\begin{tabular}{lccc}
\hline & $\begin{array}{l}\text { Non-smokers } \\
(n=87)\end{array}$ & $\begin{array}{l}\text { Current smokers } \\
(n=88)\end{array}$ & $\begin{array}{l}\text { Former smokers } \\
(n=62)\end{array}$ \\
\hline Mean & 3.06 & 16.97 & 3.68 \\
Maximum & 10 & 76 & 15 \\
Minimum & 1 & 2 & 1 \\
$95 \%$ CI & $2.66-3.45$ & $14.30-19.64$ & $2.98-4.38$ \\
\hline
\end{tabular}

In this study, the patients analysed included more smokers than the average European population, with $36.4 \%$ being smokers in group 1 (oral medicine) and $37.9 \%$ in group 2 (outpatients). In a recent study focusing on patients' awareness of the potential health benefits of smoking cessation, only $27 \%$ of the patients reported to be current smokers [20]. In contrast to this study, the patients were evaluated using self-reported data on smoking habits alone. Additionally, all patients were recruited from an oral medicine unit solely. Different results in this recent study could be due to the long enrolment period of 3.5 years, the much larger population evaluated and the fact that benefits of smoking cessation were specifically addressed and thus patients demonstrated an increased awareness of the negative impact of smoking.

Among the factors leading to a decline in cigarette smoking in the United States of America and Europe, the two most important measures in the past decade were the increase in the number of smoke-free public places and the increased taxation of cigarettes [21]. Second to the public health role of oral health professionals in general, the significance of the dentists' role in supporting their patients' attempts to discontinue tobacco use was first mentioned by Arden G. Christen in 1970 [22]. In two systematic reviews, Needleman and colleagues concluded that it was reasonable to assume that the dental setting provided a promising environment for supporting tobacco use cessation attempts $[9,23]$. In order to facilitate the adoption of tobacco use prevention and cessation (TUPAC) strategies by dental practitioners, a multilevel model of care was introduced with the recent 2nd European Workshop on Tobacco Use Prevention and Cessation for Oral Health Professionals [24, 25].
This approach includes three strategies for providing TUPAC to patients in a dental setting, with basic or brief interventions of a couple of minutes, intermediate interventions of 5-10 min and advanced interventions of $20 \mathrm{~min}$ or more. All three levels of care include an assessment of the patients' cigarette smoking habit using self-reported data. This approach is widely used, although it has been reported to underestimate the true prevalence and quantity of cigarette smoking [10-12].

Smoking behaviour of patients can be estimated by interview, self-reported questionnaire or by biochemical analysis. Simple biochemical methods to validate smoking status have been available for many years and have proven to be the gold standard [26]. Inaccurate and/or false reporting of cigarette smoking may occur for many reasons. Possible explanations may be that many patients have reported to smoke 20 cigarettes a day because this figure is the number of cigarettes per pack and may therefore serve as a convenient response. Additionally, there may be cultural pressures that influence the self-reporting of cigarette consumption [27]. More complicated but objective methods for biochemical analysis of smoking behaviour have been reported such as measurements of systemic levels of nicotine, cotinine, thyocyanate, anabasine and anatabine in plasma, saliva and urine [28]. Concerns with these techniques, regarding their implementation in a dental setting for the assessment of smoking behaviour and monitoring of TUPAC, arise from both their invasiveness and associated costs. In contrast, $\mathrm{CO}$ monitoring is a simple and inexpensive method. The cut-off value for the categorization of individuals as either positive or negative for smoking has been recommended to be 8-10 ppm [29]. $\mathrm{CO}$ measurements are reported to be reasonably specific for detecting heavy cigarette smokers, but especially for light smokers, environmental sources of $\mathrm{CO}$ of similar magnitude can pose problems in diagnosis and monitoring of smoking behaviour [30].

For the two groups analysed, the percentage of current and former smokers as well as the mean amount of cigarettes smoked per day was not statistically significantly different. Differences between the two populations evaluated were found for the cumulated pack years, where the patients in group 1 (oral medicine group) exhibited significantly higher
Table 3 Correlation between self-reported smoking status and corresponding exhaled $\mathrm{CO}$ values (in ppm) in both groups

1, non-/former smokers; 2, light smokers, 1-10 cigarettes per day; 3 , heavy smokers, more than 10 cigarettes per day

\begin{tabular}{lllll}
\hline & Never smokers & Former smokers & Current smokers & Total \\
\hline CO values from 0-6 ppm (1) & 81 & 51 & 19 & 151 \\
CO values from 7-10 ppm (1) & 5 & 10 & 9 & 24 \\
CO values from 11-25 ppm (2) & 1 & 1 & 43 & 45 \\
CO values >25 ppm (3) & 0 & 0 & 17 & 17 \\
Total & 87 & 62 & 88 & 237 \\
\hline
\end{tabular}


values. A possible explanation for this is the difference in the mean age for subjects included, with patients in the oral medicine population being almost 15 years older on average. Nevertheless, the exhaled $\mathrm{CO}$ values did not statistically significantly differ between the two groups. The self-reported smoking habits exhibited positive correlation with the exhaled CO values (Table 3), which was further expressed by the fact that one additional pack year as well as one additional cigarette smoked per day per patient resulted in statistically significant higher $\mathrm{CO}$ values of 0.16 and 0.88 ppm, respectively.

The finding that 28 out of 88 included current smokers exhibited low CO values of 2-10 ppm could have been influenced by the time of measurement for this study (8.00 a.m. to 12.00 noon). Although both serum nicotine and $\mathrm{CO}$-haemoglobin levels were found to be increased in the afternoon in heavy smokers [31], a specific or ideal time during the day for measuring exhaled $\mathrm{CO}$ levels for the assessment of current smoking behaviour has not been mentioned in the literature $[32,33]$. Thus, it seems reasonable to assume that light smokers may have not smoked a cigarette when being examined in the morning, therefore resulting in lower $\mathrm{CO}$ values. Further studies should address the influence of different measurement time points during the day on the evaluation of exhaled $\mathrm{CO}$ values, for example late morning versus late afternoon.

Although intermediate and intensive care levels for TUPAC recommended for the dental setting contain several interventions including pharmacotherapy [24, 25], a validation of self-reported smoking status versus objectively measured tobacco dependence for smoking cessation interventions in dental practices has not been addressed in the literature. The application of exhaled CO level measurements for tobacco use cessation in dentistry may be used for documentation [34] and monitoring of patients. Furthermore, the potential of this device to motivate patients to quit smoking has to be addressed. Since this study demonstrates its validity in oral care applications, future clinical trials in the dental domain should use this tool to evaluate its benefits and limits in TUPAC.

\section{Conclusions}

Based on the results of this study, exhaled CO level measurements for the assessment of current smoking behaviour of patients in a dental unit are robust and highly reproducible. Nevertheless, further studies are needed to establish the best time of day to measure exhaled $\mathrm{CO}$ values. Even though $\mathrm{CO}$ measurements have been taken between 8.00 a.m. to 12.00 noon, with all patients in this study, the correlation between self-reported smoking habits and exhaled $\mathrm{CO}$ values proved to be highly valid.
This finding was further confirmed by the fact that the consumption of an additional pack year for each smoker resulted in an increase of exhaled $\mathrm{CO}$ values by $0.16 \mathrm{ppm}$ $(p=0.003)$. Moreover, one additional cigarette smoked per day elevated the $\mathrm{CO}$ measurements by $0.88 \mathrm{ppm}(p<0.001)$. Therefore, the $\mathrm{CO}$ monitor could offer a non-invasive method in a dental setting to objectively assess current smoking behaviour and to monitor tobacco use cessation attempts especially when intermediate or intensive care levels of TUPAC are provided.

Acknowledgements The study was supported by University of Bern departmental funds and also funds from the National Stop Smoking Program of Switzerland, which is funded by the Tobacco Control Fund and the Swiss Cancer League. There are no financial relations between any author and a commercial company that may pose a conflict of interest.

\section{References}

1. Doll R, Peto R, Boreham J, Sutherland I (2004) Mortality in relation to smoking: 50 years' observation on male British doctors. BMJ 328:1097-1102

2. Patel RR, Ryu JH, Vassallo R (2008) Cigarette smoking and diffuse lung disease. Drugs 68:1511-1527

3. Gupta PC, Murti PR, Bhonsle RB (1996) Epidemiology of cancer by tobacco products and the significance of TSNA. Crit Rev Toxicol 26:183-198

4. Gandini S, Botteri E, Iodice S, Boniol M, Lowenfels $\mathrm{AB}$, Maisonneuve P, Boyle P (2008) Tobacco smoking and cancer: a meta-analysis. Int J Cancer 122:155-164

5. Johnson NW, Bain CA (2000) Tobacco and oral disease. EUWorking Group on Tobacco and Oral Health. Br Dent J 189:200 206

6. Reichart PA (2001) Identification of risk groups for oral precancer and cancer and preventive measures. Clin Oral Investig 5:207213

7. Warnakulasuriya S, Dietrich $\mathrm{T}$, Bornstein MM, Peidró EC, Preshaw PM, Walter C, Wennström JL, Bergström J (2010) Oral health risks of tobacco use and effects of cessation. Int Dent $\mathrm{J}$ 60:7-30

8. Victoroff KZ, Lewis R, Ellis E, Ntragatakis M (2006) Patient receptivity to tobacco cessation counseling in an academic dental clinic: a patient survey. J Public Health Dent 66:209-211

9. Needleman IG, Binnie VI, Ainamo A, Carr AB, Fundak A, Koerber A, Ohrn K, Rosseel J (2010) Improving the effectiveness of tobacco use cessation (TUC). Int Dent J 60:50-59

10. Daly RJ, Blann AD (1996) Self-reported smoking in vascular disease: the need for biochemical confirmation. Br J Biomed Sci 53:204-208

11. Coultas DB, Howard CA, Peake GT, Skipper BJ, Sarnet JM (1988) Discrepancies between self-reported and validated cigarette smoking in a community survey of New Mexico Hispanics. Am Rev Respir Dis 137:810-814

12. Gorber SC, Schofield-Hurwitz S, Hardt J, Levasseur G, Tremblay M (2009) The accuracy of self-reported smoking: a systematic review of the relationship between self-reported and cotinine-assessed smoking status. Nicotine Tob Res 11:12-24

13. Scherer G, Richter E (1997) Biomonitoring exposure to environmental tobacco smoke (ETS): a critical reappraisal. Hum Exp Toxicol 16:449-459 
14. Ramseier CA, Mattheos N, Needleman I, Watt R, Wickholm S (2006) Consensus report: First European Workshop on Tobacco Use Prevention and Cessation for Oral Health Professionals. Oral Health Prev Dent 4:7-18

15. Ramseier CA, Bornstein MM, Saxer UP, Klingler K, Walter C (2007) Tobacco use prevention and cessation in the dental practice. Schweiz Monatsschr Zahnmed 117:253-278, in German

16. Andersson MF, Moller AM (2010) Assessment of carbon monoxide values in smokers: a comparison of carbon monoxide in expired air and carboxyhaemoglobin in arterial blood. Eur J Anaesthesiol 27:812-818

17. Middleton ET, Morice AH (2000) Breath carbon monoxide as an indication of smoking habit. Chest 117:758-763

18. Watt RG, Benzian H, Binnie V, Gafner C, Hovius M, Newton TJ, Mecklenburg RE (2006) Public health aspects of tobacco control: setting the agenda for action by oral health profession across Europe. Oral Health Prev Dent 4:19-26

19. Gallagher JE, Alajbeg I, Büchler S, Carrassi A, Hovius M, Jacobs A, Jenner M, Kinnunen T, Ulbricht S, Zoitopoulos L (2010) Public health aspects of tobacco control revisited. Int Dent J 60:31-49

20. Bornstein MM, Frei M, Sendi P, Ramseier CA, Reichart PA (2010) Patients' awareness of the potential benefit of smoking cessation. A study evaluating self-reported and clinical data from patients referred to an oral medicine unit. Clin Oral Invest. doi:10.1007/ s00784-010-0488-5

21. Black JH 3rd (2010) Evidence base and strategies for successful smoking cessation. J Vasc Surg 51:1529-1537

22. Christen AG (1970) The dentist's role in helping patients to stop smoking. J Am Dent Assoc 81:1146-1152

23. Needleman I, Warnakulasuriya S, Sutherland G, Bornstein MM, Casals E, Dietrich T, Suvan J (2006) Evaluation of tobacco use cessation (TUC) counselling in the dental office. Oral Health Prev Dent 4:27-47

24. Davis JM, Ramseier CA, Mattheos N, Schoonheim-Klein M, Compton S, Al-Hazmi N, Polychronopoulou A, Suvan J, Antohé ME, Forna D, Radley N (2010) Education of tobacco use prevention and cessation for dental professionals - a paradigm shift. Int Dent J 60:60-72

25. Ramseier CA, Warnakulasuriya S, Needleman IG, Gallagher JE, Lahtinen A, Ainamo A, Alajbeg I, Albert D, Al-Hazmi N, Antohe
E, Beck-Mannagetta J, Benzian H, Bergstrom J, Binnie V, Bornstein M, Buchler S, Carr A, Carrassi A, Peidro EC, Compton S, Crail J, Crews K, Davis JM, Dietrich T, Enmark B, Fine J, Gallagher J, Jenner T, Forna D, Fundak A, Gyenes M, Hovius M, Jacobs A, Kinnunen T, Knevel R, Koerer A, Labella R, Lulic M, Mattheos N, McEwen A, Needleman I, Ohrn K, Polychronopoulou A, Preshaw P, Radley N, Ramseier C, Rosseel J, Schoonheim-Klein M, Suvan J, Ulbricht S, Verstappen P, Walter C, Wennstrom J, Wickholm S, Zoitopoulos L (2010) Consensus report: 2nd European workshop on tobacco use prevention and cessation for oral health professionals. Int Dent J 60:3-6

26. Scott DA, Palmer RM, Stapleton JA (2001) Validation of smoking status in clinical research into inflammatory periodontal disease. $\mathrm{J}$ Clin Periodontol 28:715-722

27. Wells AJ, English PB, Posner SF, Wagenknecht LE, Perez-Stable EJ (1998) Misclassification rates for current smokers misclassified as nonsmokers. Am J Public Health 88:1503-1509

28. SNRT Subcommittee on Biochemical Verification (2002) Biochemical verification of tobacco use and cessation. Nicotine Tob Res 2002 (4):149-159

29. Raiff BR, Faix C, Turturici M, Dallery J (2010) Breath carbon monoxide output is affected by speed of emptying the lungs: implications for laboratory and smoking cessation research. Nicotine Tob Res 12:834-838

30. Taniguchi S, Niitsuya $\mathrm{M}$, Inoue $\mathrm{Y}$, Katagiri $\mathrm{H}$, Kadowaki $\mathrm{T}$, Aizawa Y (1999) Evaluation of passive smoking by measuring urinary trans, trans-muconic acid and exhaled carbon monoxide levels. Ind Health 37:88-94

31. Zevin S, Gourlay SG, Benowitz NL (1998) Clinical pharmacology of nicotine. Clin Dermatol 16:557-564

32. Simmons MS, Connett JE, Nides MA, Lindgren PG, Kleerup EC, Murray RP, Bjornson WM, Tashkin DP (2005) Smoking reduction and the rate of decline in $\mathrm{FEV}(1)$ : results from the Lung Health Study. Eur Respir J 25:1011-1017

33. Hughes J, Lindgren P, Connett J, Nides M (2004) Smoking reduction in the Lung Health Study. Nicotine Tob Res 6:275280

34. Nasry HA, Preshaw PM, Stacey F, Heasman L, Swan M, Heasman PA (2006) Smoking cessation advice for patients with chronic periodontitis. Br Dent J 200:272-275 